\title{
Chapter 33 \\ 3D Modeling of the Cadastre \\ and the Spatial Representation of Property
}

\author{
Lin Li, Renzhong Guo, Shen Ying, Haizhong Zhu, Jindi Wu, \\ and Chencheng Liu
}

\begin{abstract}
An emerging technology, three-dimensional (3D) cadastres as extensions to the current parcel-based or two-dimensional (2D) cadastre, has been developed to meet the management of 3D urban land use and 3D properties. This chapter provides a brief review of the key issues of 3D cadastre and the spatial representation of ownership. In order to understand the importance of legislation for developing modeling technology for 3D property, the legislative context of ownership is addressed in specific reference to China. In light of spatial rights of land-use space, a 3D spatial model of property is presented in terms of polyhedra with four-layer structures. Being compatible with the existing 2D cadastre, this 3D spatial data structure is suitable as a hybrid cadastral system for 2D and 3D property and provides an available means to spatially represent 3D property with integrity. By analyzing the heterogeneity of the land space used for property, the ownership of condominiums with internal structure is addressed and spatial representation of ownership is presented by instantiation in a case study in China.
\end{abstract}

\subsection{Introduction}

A cadastre is generally regarded as a comprehensive land recording of the metes and bounds of a country's real property. According to the International Federation of Surveyors (FIG), a cadastre is normally a parcel-based and up-to-date land information system containing an official record of interests in land (i.e., rights, restrictions, and responsibilities or RRRs). In this record, the ownership, extent, and value of real property in a given area are explicitly and clearly registered and used for fiscal purposes (e.g., taxation), legal purposes, and to assist in the management of land and

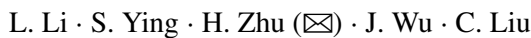

School of Resource and Environmental Sciences, Wuhan University, Wuhan, China

e-mail: hhzhu@whu.edu.cn

R. Guo

Research Institute for Smart City, Shenzhen University, Shenzhen, China

(C) The Author(s) 2021

W. Shi et al. (eds.), Urban Informatics, The Urban Book Series,

https://doi.org/10.1007/978-981-15-8983-6_33 
land use (e.g., for planning and other administrative purposes). Registration of RRRs is the administrative core of cadastres and properties.

As ownership is defined as the lawful record of a property or a piece of land assigned to the people who own the property, the spatial extent and geographical location of the property are the critical elements for substantiating the ownership. Traditionally, a piece of land defined as a land parcel (or simply, a parcel) is a plane area with a clear boundary on the surface of the Earth. From the boundary on the ground, a spatial "cone" can be formed geometrically from the Earth's center to the sky, and ownership implicates the lawful record of all things within the spatial "cone." In this sense, the rights to land within the "cone" (space on, below, and above the ground) are hypothetically homogeneous and can be easily demarcated by the plane's extent. As such, a two-dimensional (2D) or parcel-based cadastre has so far dominated the administration of cadastres and has been adopted by various legal systems.

With the evolution of society and the economy, especially in urban areas, rapid urbanization presents a challenge to densely populated cities with limited urban land resources, and changes to land-use patterns in the form of urban sprawl have been increasing in recent years (Foley et al. 2005; Turner et al. 2007; Guo et al. 2013; Zulkifli et al. 2015; Li et al. 2016). Space on, below, and above the ground cannot be used merely for a single purpose. A piece of land must be shared by various parties for different contexts, and rights to it cannot be secured by its plane extent. The rights bounded to the space below or above ground are no longer fully consistent with that on the ground. Thus, the use of a land parcel in terms of cadastre inevitably evolves into the more general use of land space, which leads to a shift of focus from the surface of land parcels to the space above and below them in land use and development.

The emerging, spatially heterogeneous rights to land parcels break the spatial homogeneity of land rights within the cone, as long as required by the $2 \mathrm{D}$ parcelbased cadastre. The traditional concept of the $2 \mathrm{D}$ cadastre is augmented by dividing the utilization of land space vertically, in order to accommodate increased population density and intensive socioeconomic activities in urban areas. Three-dimensional (3D) cadastres have been developed to meet the management of 3D land-use space and 3D property (Guo et al. 2013; Stoter et al. 2013; Jazayeri et al. 2014; Karabin 2014). This emerging technology helps meet the increasing social demand for the precise management of immovable property (land and housing).

Here, a typical example quoted from the study by Guo et al. (2013) may present an intuitive understanding of the deficiency of a parcel-based cadastre. They cite a parcel with a complex building on it in Shenzhen, one of the fastest-growing and most economically advanced cities in China. This complex is made up of several plaza buildings containing many shops. Two main buildings are separated by a municipal road and connected by an arched structure. The buildings are registered on a parcelbased cadastral map (Fig. 33.1). The land space used for the over-ground arch is drawn on this map and labeled with H102-0037(B), which overlaps with the commercial shops and the underground parking lot. Two adjacent parcels, H102-0037 and H1020038, contain the two main buildings, respectively. However, H102-0037(B) refers to the parcel above the surface, while H102-0037 and H102-0038 refer to parcels on the surface. The land space of the arch, a public pedestrian corridor (a kind of easement), belongs to the municipality, while the underground shops above the parking lot are 
Fig. 33.1 Cadastral map (Guo et al. 2013)

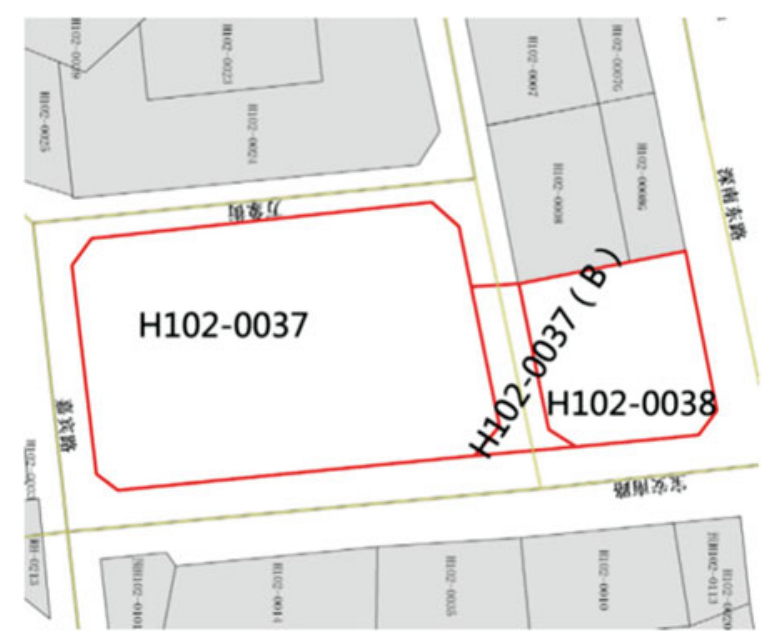

Fig. 33.2 The vertical profile of construction (modified from Guo et al. 2013)

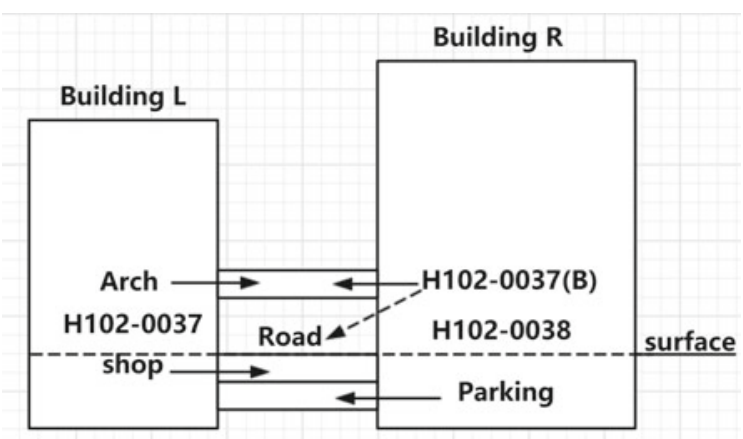

owned by different individuals. The vertical configuration is illustrated in Fig. 33.2. However, it is found that this $2 \mathrm{D}$ cadastral map fails to record the spatial configuration of land space and may even confuse readers. The implications of a multi-purpose use of land in H102-0037(B) could not be geometrically clarified on the 2D cadastral map without adding a third dimension.

\subsection{Spatial Rights to Real Property}

\subsubsection{Legal Context of a 3D Cadastre}

When real property or a cadastre is registered on a $2 \mathrm{D}$ cadastral map, spatial rights to real property, or the spatial extents assigned by ownership, can only be directly presented in terms of $2 \mathrm{D}$ geometry, even though the rights are legally attributed in 
3D. As the above example shows, a 2D cadastre cannot represent the $3 \mathrm{D}$ features of property. As the spatial rights are prescribed, interpreted, and implemented within legal systems, it is important to understand the legal context in order to model the spatial extent of the rights.

Ownership of land, or property in a wider sense, is set by legal systems and social conventions. The key issue in land administration is the management of various property or spatial rights on, in, and attached to the piece of land. These rights are embodied in the concept of property, which may have different meanings in different countries (Kalantari et al. 2008; Stubkjær 2004) that are largely dependent on legal systems (Paulsson and Paasch 2011). Some countries-such as the Netherlands, Germany, the UK, France, and Belgium - define ownership as the rights to the ground and of all space above and below it, including groundwater and fixtures (van der Molen 2003). Other countries understand ownership in a way that does not include mines and groundwater. Some jurisdictions may not allow separate rights to a parcel from construction on it, such as in the Netherlands and China. Other nations, such as Denmark, accept, through leasing, different ownerships for land and for buildings; in fact, the formation of a property "on top of another property" can be implemented under a special procedure (Sorensen 2011).

As most systems of land administrations in the world are set on the basis of 2D cadastres, the development of a 3D cadastre requires the amendment of property laws and regulations when land use extends spatially to a vertical from a horizontal plane. This is a big issue especially for those developed countries with comprehensive legal and administrative systems. It usually takes a quite long and arduous effort to finish an amendment. However, the laws in developing countries or regions are likely to be amended more easily than those of developed countries due to their imperfect legislation and administration.

China is a rapidly developing country and is currently perfecting her legislation and administration, which gives her room to adapt, update, or refine some items in her property laws where spatial rights of property have not been defined in great detail. It was in 2007 when the Real Right Law of the People's Republic of China was issued and took effect (October 1, 2007). The right to land is founded also on the principles of the parcel-based cadastre; however, Article 136 in this law states that "the right to use construction land may be created separately on the surface of or above or under the land. The newly established right may not injure the usufructuary right that has already been established." Article 138 further states that land space occupied by buildings, fixtures, and affiliated facilities shall be contained in a contract with the transfer of rights.

The separation of property rights for construction above and underground from those on the surface implies that uses of above and underground spaces may be different from those of the surface and that the parcel space may be multi-level, across boundaries, or without 2D geometric limitation. It indicates that the rights to land are always associated with some construction and no ownership will be created without construction (or buildings). This law provides a good legal basis for local governments to create their own rules and regulations for land use and makes it easier to develop a $3 \mathrm{D}$ cadastral system than in more developed countries or regions. 


\subsubsection{Geometry of 3D Property with Homogeneous Land Space}

A property has both bona fide and legal aspects (Aien et al. 2013; Jazayeri et al. 2014; Ying et al. 2014), and it is considered a compound object that combines the physical object with the legal treatment of the object. The physical object (such as a usable unit of land space or an apartment) takes certain geometry and is the base of the ownership and other rights. The legal aspect of property is attached to the physical object and refers to or involves more space in various senses; for example, solar rights to an apartment involve a space beyond the space occupied just by the apartment and without a clearly defined boundary (Li et al. 2019). Thus, the spatial representation of the physical objects is the major task of modeling 3D property that is explicitly defined by spatial extent in the physical 3D space, that is, modeling ownership by spatial means.

As a building is always attached on a piece of land, a 3D property (containing both land and building or construction) consists spatially of two 3D geometries: a 3D model of the construction and a 3D container that is a derived spatial extent of land space used by the construction. Since a 3D model of construction is included in the container, the spatial relation of a property with others can be captured by the spatial relation among the containers. The architectural configuration of the construction may have some influence on rights to land space, such as the geometry of easement on neighboring spaces, and will be shaped by the access points of the architecture. However, this kind of influence is hardly depicted in an explicit geometry. Therefore, in terms of the cadastre, spatial modeling of a property in the form of land space is aimed at presenting an explicit 3D geometry of the containers, which simplifies the geometry of a property into a polyhedron. It comprises a prism or a combination of prisms that have vertical faces and flat tops or bottoms (Fig. 33.3).

Fig. 33.3 Geometry of 3D property in a cadastre

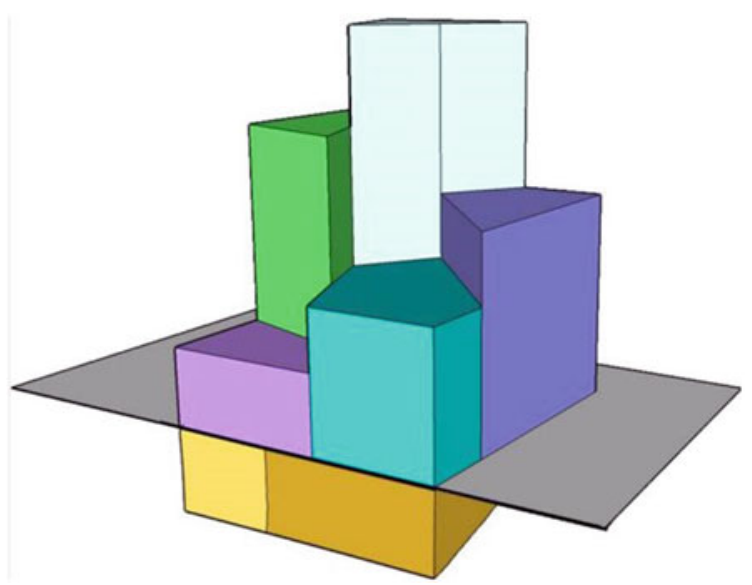


This simplicity results from the fact that land space for above or underground construction is plotted depending on a planar parcel. The faces of a polyhedron and the edges of the faces should satisfy the generalized Jordan curve theorem that refers to the orientability of these geometric elements. The interior of the container is hypothetically connected, which means that any container is simple, and no compound or multiple containers are allowed. If a container can be divided into two or more independent containers, each of the latter is treated as a simple one.

\subsection{Integral Spatial Modeling of 3D Property}

Spatial modeling of 3D objects long has been studied and is being addressed in the domain of geographical information systems (GIS) and related fields. Many 3D data models have been presented and are used to capture the spatial features of 3D objects in terms of geometry. 3D objects may be featured by simplexes (point, line, triangle, and tetrahedron; Carlson 1987), configured by a 3D formal data structure (FDS) (Molenaar 1990), represented by tetrahedronized irregular networks (Penninga et al. 2006), by polyhedra (Arens et al. 2005; Stoter 2004; Wenninger 1974; Zlatanova 2000), by polyhedral regular polytopes (Thompson 2007), or by a constructive solid geometry (CSG) and B-rep approach in computer graphics. Those data models have been commonly used for different fields and applications with certain semantic foci.

In spatially modeling of land administration and registration of property, an emphasis is placed on keeping these data consistent when developing a real 3D cadastre and extending its spatial dimension from $2 \mathrm{D}$, since the semantics embedded in the data models are used to regulate and coordinate relationships among people and property under a given society, economy, and legal system. Therefore, the data model of $3 \mathrm{D}$ property should be compatible with the existing data model in $2 \mathrm{D}$ parcel-based cadastral systems so that the semantics recorded in the latter will not change.

The 2D data models with three-layer structure including topological featuresfaces, edges, and nodes (vertices) - are commonly adopted in 2D cadastre. A simple example is shown in Fig. 33.4 with Table 33.1, where an edge is terminated by its two nodes and a face is represented by its surrounding boundary as a series of edges. For example, in that figure f14 is composed of four edges $\{\mathrm{e} 25, \mathrm{e} 26, \mathrm{e} 27$, and e28 $\}$.

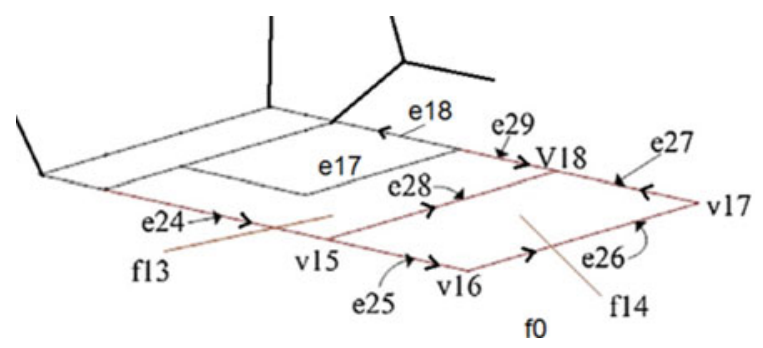

Fig. 33.4 2D data model for parcel-based property 
Table 33.1 Table of the 2D data model shown in Fig. 33.4

\begin{tabular}{l|l|l|l|l}
\hline Edge & From_Node & To_Node & Left_Face & Right_Face \\
\hline$\ldots$ & & & & \\
\hline e25 & v15 & v16 & f14 & f0 \\
\hline e26 & v16 & v17 & f14 & f0 \\
\hline e27 & v17 & v18 & f14 & f0 \\
\hline e28 & v15 & v18 & f13 & f14 \\
\hline$\ldots$ & & & & \\
\hline
\end{tabular}

Adding a 3D topological feature - a volume - to the 2D data model forms a 3D data model with four-layer structure for the 3D cadastral system. Consequently, a volume that is able to depict a container or polyhedron is represented by a set of faces that enclose a 3D space. Such a 3D data model may be operationally structured with a 3D piecewise linear complex (PLC), a commonly used geometric data structure in computer graphics (Cohen-Steiner et al. 2004; Miller et al. 1996; Si and Gartner 2005).

For example, two volumes (3D properties) in Fig. 33.5a are integrated with 2D parcels into a $3 \mathrm{D}$ spatial configuration of $3 \mathrm{D}$ space that accommodates both $2 \mathrm{D}$ properties and 3D properties shown in Fig. 33.5b. Volume Vol2 is represented by an

(a)

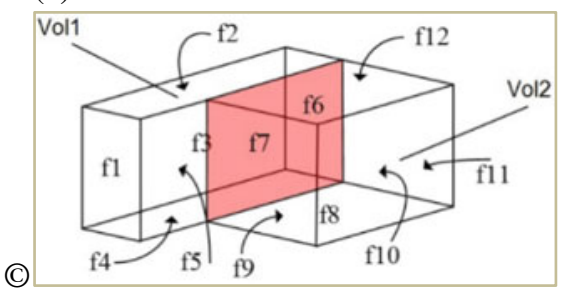

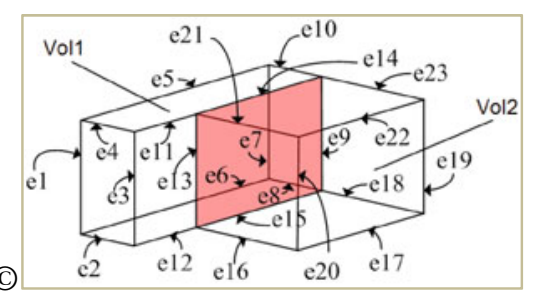

(b) Vol 1

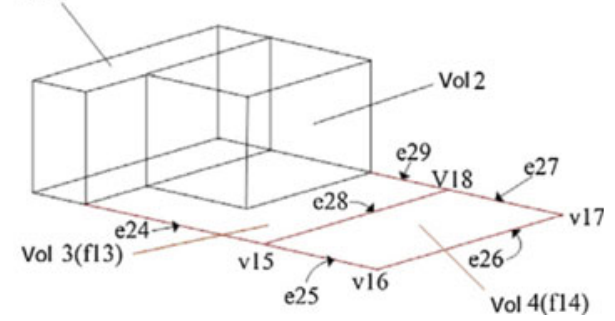

Fig. 33.5 A 3D data model of property compatible with a parcel-based 2D data model (modified from Guo and Ying 2010). a Two volumes (containers) with 3D geometry. b Compatible data model for $2 \mathrm{D}$ and $3 \mathrm{D}$ cadastre 
enclosed face set $\{\mathrm{f} 7, \mathrm{f} 8, \mathrm{f} 9, \mathrm{f} 10, \mathrm{f} 11, \mathrm{f} 12\}$, and face $\mathrm{f} 8$ is demarcated by a set of edges $\{$ e15, e16, e17, e18\}. Volume Vol4 is regarded as a special kind of 3D object, being degraded from 3D geometry into face f14 of the 2D geometry. This simple example shows that the $3 \mathrm{D}$ data model matches well with the commonly used $2 \mathrm{D}$ data model.

\subsection{Heterogeneity of Land Space Used for Property}

If an ownership includes a certain land space where all constructions lie within the space, a container mentioned above in the form of a polyhedron can be spatially modeled due to its homogeneous space with respect to ownership. However, in a densely populated urban area, many high-rise buildings are created to provide more housing and to accommodate more people. A unique owner of an apartment in a building is not an exclusive owner of a parcel of land that is undividable. Although an apartment uniquely occupies a chunk of land space and its ownership could be also spatially modeled by its polyhedral container geometry, different legal treatments associated with the ownership emerging from sharing integrity of land space break the homogeneity of the land space used by the apartment. In this case, the internal structure of the ownership should be clearly presented by its spatial representation. This poses a critical requirement for more precise management of property that includes not only land space and the vertical spatial extent of the property, but also the horizontal extent of the property and the ownership structure, which corresponds to the spatial components of the property.

In general, a property being viewed as a compound object combines the physical object with the legal treatment of the object in data models. However, a physical object (building or apartment) may be constructed with several parts with different functions or intentions, which lead to different legal treatments included in the ownership. An internal heterogeneity is then emerging in the ownership and reflects the disparity of the lawful recording of the different parts of an object and requires differentiating ownership in a property management system. A condominium unit is a typical property of this kind.

With a common or shared ground parcel, a building consisting of condominiums is divided into private and common parts. This co-ownership has been discussed by many studies (Çă̆daş 2013; Pouliot et al. 2011, 2013; Rajabifard et al. 2013; Li et al. 2016). For this kind of ownership two types of ownership are found, exclusive ownership and shared ownership. Exclusive ownership means that an owner can dispose of his or her parts according to the corresponding laws. Shared (or common) ownership means that the common parts and the ground parcel cannot be disposed at someone's own will and must be disposed in common. It is also found that an ownership of a condominium is not the same as ownership of a piece of parcel or a chunk of land space. Its different spatial parts with certain rights should be represented in detail so that the internal structure of the ownership is expressed in a spatially explicit manner targeted toward more precise management of property. 
Physical structural components associated with a condominium unit may have different rights to each part with internal homogeneity and those different rights come together to constitute the ownership of the condominium. For example, in China, an ownership of a condominium unit may include two physical objects: the exclusively owned apartment itself and some space (such as elevators and corridors) that is shared with others. The ownership includes at least two different internal rights to the parts. Even for exclusively owned objects (or spaces), the room space is physically recorded into the legal spatial extent, and a balcony (space) may be half-recorded into the legal spatial extent. Such subdivisions of ownership with legal space are critical in taxation, loans, and insurance.

As parts of land space corresponding to certain physical objects, each of these parts in general can be suitably modeled by an enclosed polyhedron in the four-layer structure. However, it becomes critical to clarify the semantics of those parts with ownership and spatial relations among them in spatial modeling of the ownership. As mentioned above, the meaning of ownership varies with different legal systems and social conventions; it would be much more helpful to discuss the spatial representation of the condominium ownership with a given legislative and institutional context. The following section uses China as an example.

\subsection{A Case Study of Spatial Modeling of Ownership Structure in China}

\subsubsection{Ownership of Condominiums in China}

According to the Land Administration Law in mainland China, urban land is administered differently from rural land. Any urban land is uniquely owned by the State and ownership cannot be altered. Ownership of the buildings or other constructions on urban land can be attributed to individuals or any legal parties. A property embodies the ownership of a house, a building, or buildings and the usufruct of land. In this legislative context as well as social conventions in China, condominiums are the predominant form of housing property in urban areas. Ownership is legislatively ensured by the Real Right Law of the People's Republic of China (People's Republic of China 2007), which offers provisions for the owners' co-ownership of building areas. Its Article 70 states that "as regards such exclusive parts within the buildings as the residential houses or the houses used for business purposes, an owner shall enjoy the ownership thereof, while as regards the common parts other than the exclusive parts, the owner shall have common ownership and the common management right thereof."

Ownership of a condominium unit refers to two types of objects, that is, exclusive objects and common or shared objects. In Specifications for Estate Surveying (People's Republic of China 2000), exclusive objects are further divided into two types of objects: the major body and annexes such as balconies, basements, 
Table 33.2 Internal structure of ownership of a condominium unit

\begin{tabular}{l|l|l|l|l}
\hline Physical parts & Physical objects & Sub-objects & $\begin{array}{l}\text { Counted physical } \\
\text { space }\end{array}$ & Remarks \\
\hline \multirow{2}{*}{ Exclusive } & Major body & & Completely & Rooms \\
\cline { 3 - 5 } & Annexes & De facto & Totally & $\begin{array}{l}\text { Balconies in the } \\
\text { major structure }\end{array}$ \\
\cline { 3 - 5 } & Ratio & Partially & $\begin{array}{l}\text { Balconies outside of } \\
\text { the major structure }\end{array}$ \\
\cline { 3 - 5 } & \multirow{2}{*}{ Fiat } & $\begin{array}{l}\text { Non (height }< \\
2.1 \text { m) } \\
\text { Partially (others) }\end{array}$ & Bay windows \\
\hline \multirow{2}{*}{ Shared } & Dertionable & De facto & Totally & $\begin{array}{l}\text { Commonly owned } \\
\text { indoor stairs }\end{array}$ \\
\cline { 3 - 5 } & Ratio & Partially & $\begin{array}{l}\text { Commonly owned } \\
\text { corridors }\end{array}$ \\
\cline { 3 - 5 } & Non-apportionable & & Non & $\begin{array}{l}\text { Commonly owned } \\
\text { roof gardens }\end{array}$ \\
\cline { 3 - 5 } & \multirow{2}{*}{ Fiat } & Non & Basements \\
\hline
\end{tabular}

and garages; common objects are further divided into apportionable and nonapportionable objects. Construction area is used to measure ownership in terms of magnitude. Apportionable means that the metric geometry of the objects is calculated in some approach to contribute the construction area of the corresponding condominium units, and non-apportionable means that the objects make no contribution to the construction area. That is, the legal construction area of a condominium unit consists of the construction area from its exclusive parts and from its shares of apportionable objects.

Since the spatial extent of physical objects from both types is the metric base for deriving the construction area and measures ownership in different ways, ownership of a condominium unit is structured by different parts in light of the physical configuration of the unit and buildings including the unit. The internal structure of ownership is tabulated in Table 33.2.

\subsubsection{Implementation Tool for Spatial Modeling of Ownership}

It is very clear from Table 33.2 that the structure of ownership can be presented by a 3D model of the physical building of a condominium unit. Although a condominium unit may be of complex physical structure, each part corresponds to a physical component of the building which can be modeled with the geometry of a 3D container as discussed above. It is known that CityGML models or building information models (BIMs) provide rich semantic and $3 \mathrm{D}$ information for the internal structure of a 
building (Li et al. 2019). A great effort has been made to adopt CityGML or BIMs in the field of land administration and property management (Amirebrahimi 2012; Çağdaş 2013; El-Mekawy et al. 2014; Góźdź et al. 2014). CityGML has shown its merits in exploring the internal heterogeneity of the ownership of condominiums and clarifying the spatial differences within the ownership.

The ISO19152 LADM is designed for offering a conceptual model that allows land administration objects and relationships to be described. Land administration is described as the process of determining, recording, and disseminating information on the relationship between people and land (or rather space). The LADM includes basic packages that are related to (1) parties; (2) basic administrative units and RRRs; and (3) spatial units (parcels, legal spaces of buildings, and utilities). The package, Spatial Unit, is composed of the surveying and spatial representation sub-packages, and has several different spatial profiles that describe geometrical and topological aspects. This package provides an available linkage to 3D models of building structures.

Although LADM and CityGML have different foci on spatial features, there is no obvious geometrical barrier between them because both LADM and CityGML are compatible with ISO19107. LADM provides a formal language to describe land administration in terms of its parties, administrative and spatial units, and sources and representations, while CityGML is a data encoding method that was created to exchange data. The representation of legal spaces from LADM can be mapped to and encoded as a CityGML ADE (application domain extension mechanism) (OGC 2012; Çağdaş 2013). That is, CityGML with LADM offers an effective way to develop a feasible 3D cadastral system which is able to model either homogeneous spatial rights of $3 \mathrm{D}$ property with integrity, or heterogeneous spatial rights with internal structure of ownership.

\subsubsection{An Example of Spatial Representation of the Internal Structure of Ownership}

A case study of a condominium in China ( $\mathrm{Li}$ et al. 2016) is borrowed here as an example of the spatial modeling of the internal structure of ownership by CityGML with LADM. Modeling the ownership structure of a condominium unit is shown in Fig. 33.6. LADM packages (red color) are introduced and two separate hierarchies, a legal hierarchy (yellow color) and a physical hierarchy (light blue color), are modeled with CityGML independently, and an $n: n$ relationship between these is established in the model. As a building unit might have a different legal spatial extent from its physical counterparts, an attribute "the numerical ratio" is designated as the ratio of the legal spatial extent to its physical spatial extent, such as $0.5,1$, or 0 for different types of building parts. Therefore, the legal spatial extent and relevant semantic information are attached to and combined with a corresponding physical object by extending the attributes and semantics in CityGML, which is implemented through the usage of the ADE mechanism. The legal object is described by its physical 


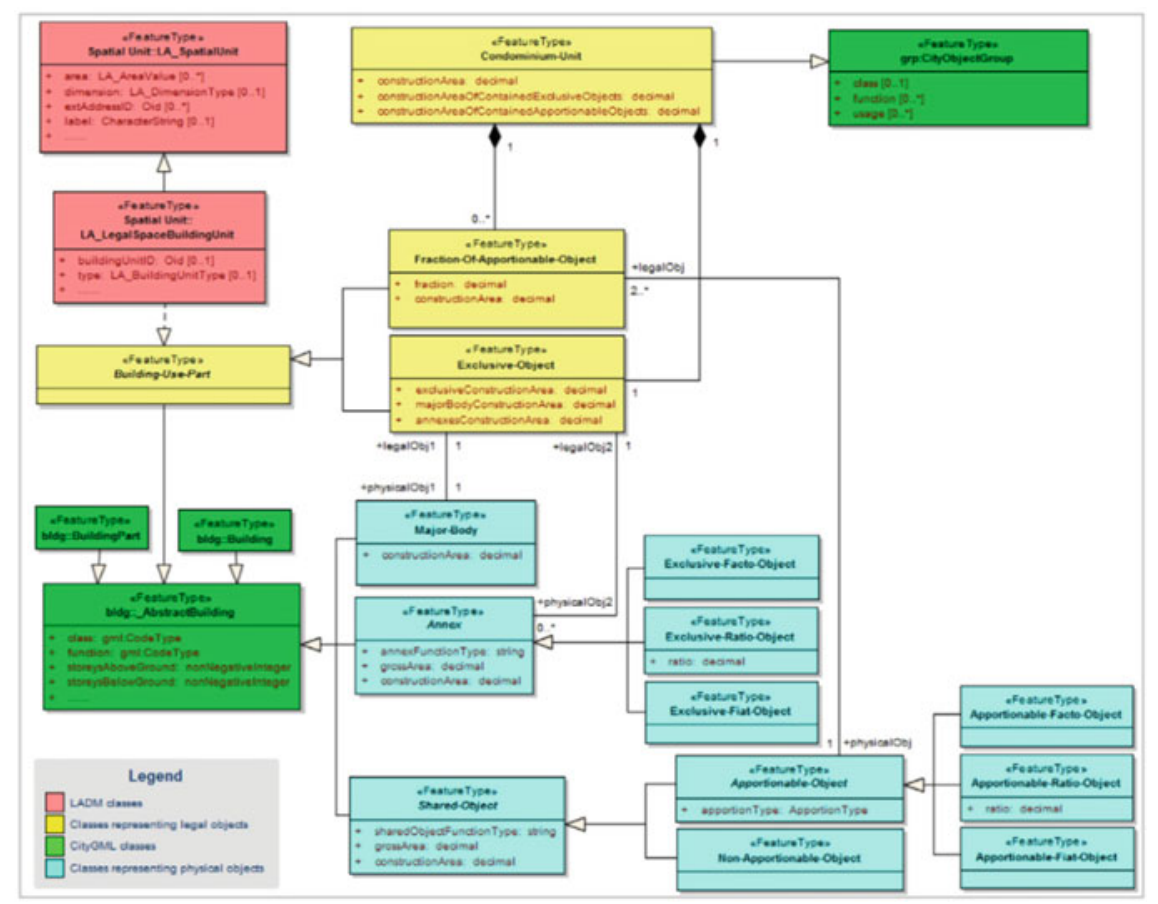

Fig. 33.6 UML diagram for modeling the ownership structure of a condominium unit ( $\mathrm{Li}$ et al. 2016)

counterpart via semantic relations between them, which is also implemented by the use of the ADE mechanism.

A residential condominium with 28 stories is taken as an example of modeling. The internal structures of each story are similar to each other, so only the second story is viewed here. Three exclusive objects and seven shared objects are on this story. Each exclusive object is composed of one major body and some annexes, including de facto annexes, ratio annexes, and fiat annexes (Fig. 33.7). Apportionable de facto objects are also included, such as shared objects within a building (such as staircases) and shared objects in this story (such as corridors), apportionable ratio objects (such as a lanai), and apportionable fiat objects (such as a commonly used flowerbed).

Figure 33.8 shows the 3D representation of the interior structure of this second story. The semantic relations of the condominium units with their exclusive components and their physical counterparts in the second story, including the major bodies and annexes, are presented, for instance, in Fig. 33.9, which shows the semantic relations of Condominium Unit 1.

This example shows that although the ownership of a condominium unit is inherently complex, the internal structure can be subdivided into several sections in terms of homogeneity of rights, and the ownership structures can be modeled precisely by extending CityGML with the LADM. The spatial model here is mainly based on legal concepts specified by legislation in China. However, the modeling approach 


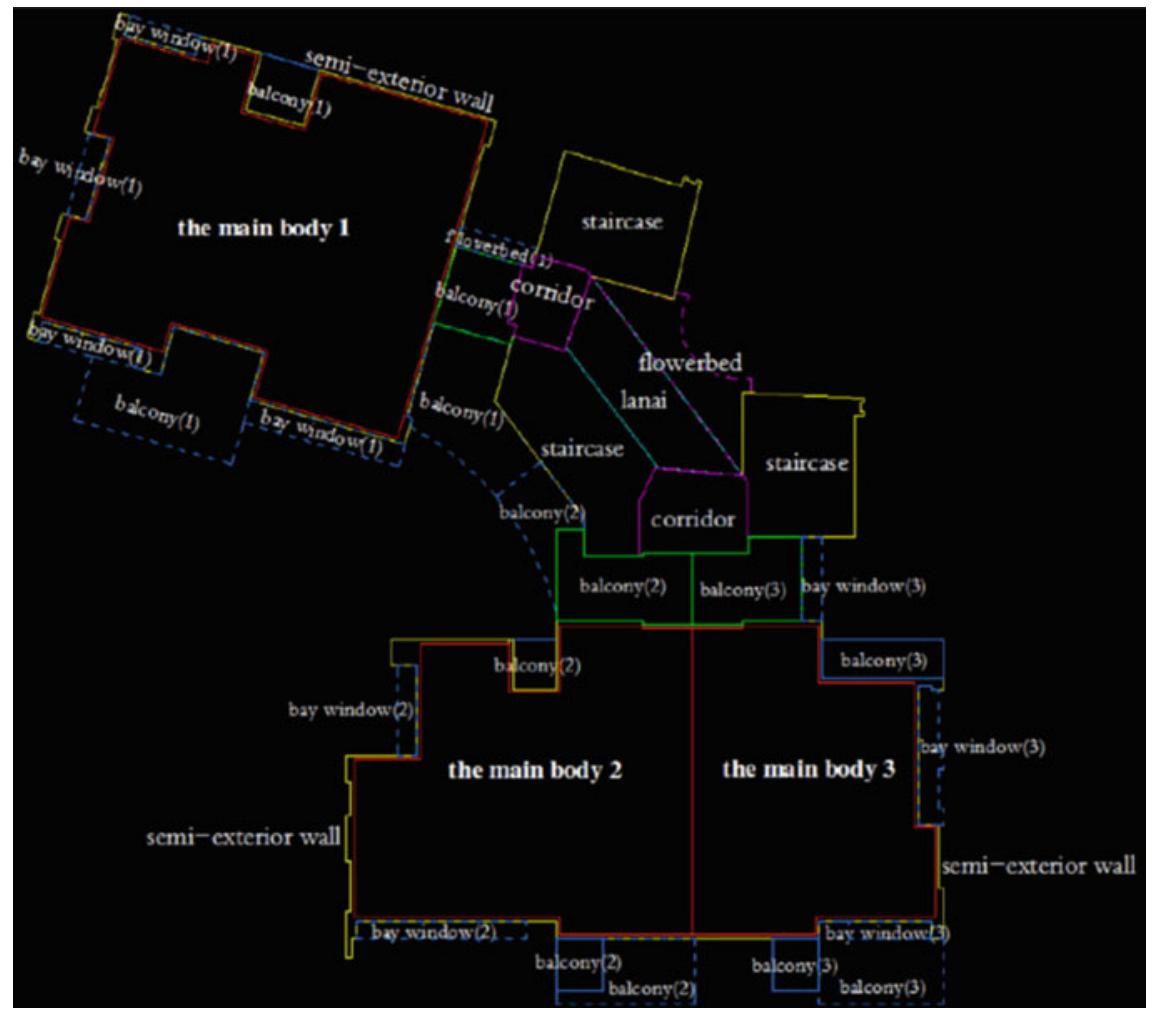

Fig. 33.7 Layout plan of the second story of the residential condominium building (Li et al. 2016). Red solid line: the major body; blue solid line: exclusive de facto object; green solid line: exclusive ratio object; blue dotted line: exclusive fiat object; yellow solid line: apportionable de facto object that is shared in the building; magenta solid line: apportionable de facto object that is shared in the story; cyan solid line: apportionable ratio object; magenta dotted line: apportionable fiat object; and number in brackets after the names of the annexes: the number of the major body to which the annexes are attached

may provide an available paradigm to model the ownership structure of a condominium unit, which could be adapted to other jurisdictions, especially in countries where similar legal concepts exist.

\subsection{Summary}

A transition in the administration of land or immovable property from land parcel (2D) to land space (3D) is a trend in urban areas, especially in populated cities, owing to both an increasing intensity of socioeconomic activities and a need to update to 3D technology. Although some rights to property may be completely or 


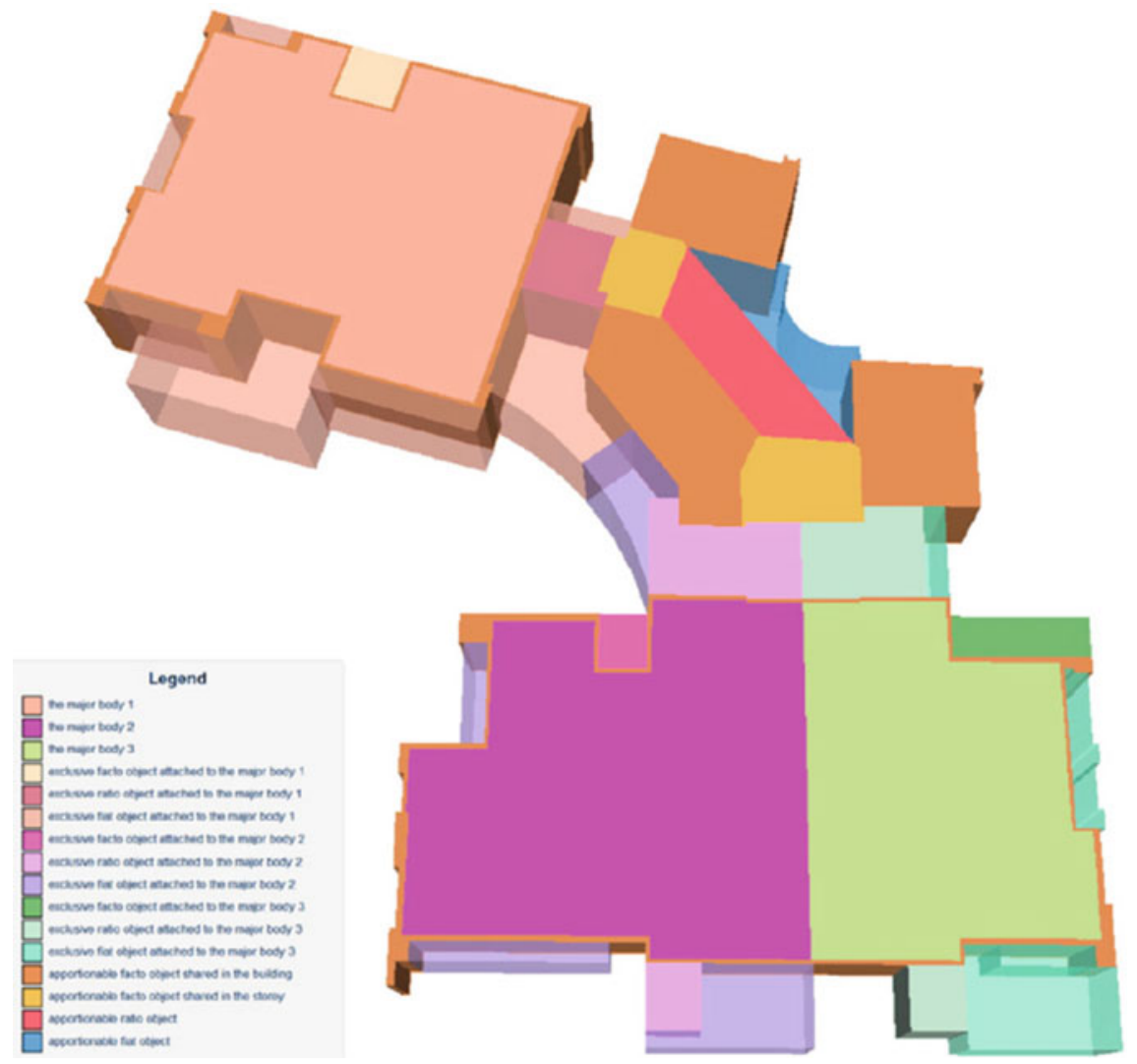

Fig. 33.8 3D representation of the interior structure of the second story (Li et al. 2016)

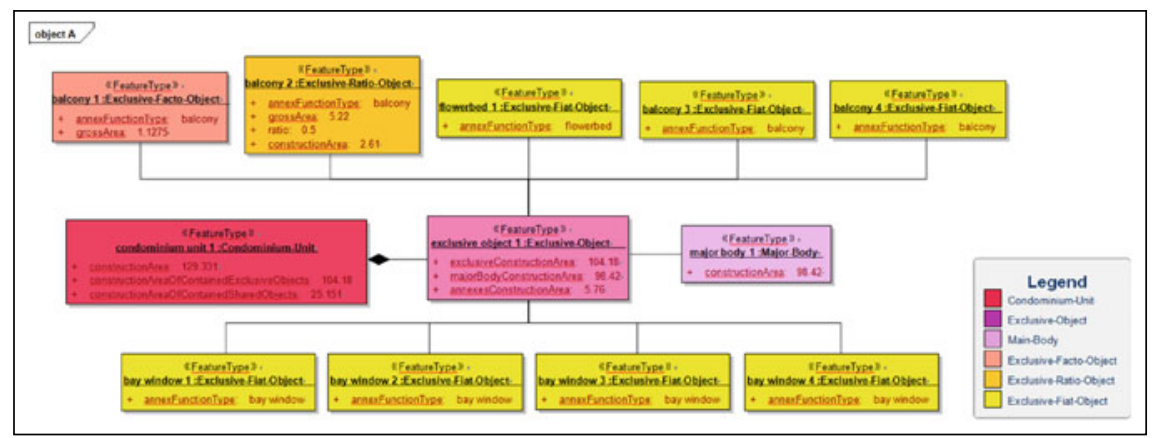

Fig. 33.9 Semantic relations between Condominium Unit 1 and its exclusive components ( $\mathrm{Li}$ et al. 2016) 
partially unclear with respect to space, the nature of the rights characterized by spatial features is crucial in managing and clarifying them. The use of the vertical space above and below ground, rather than horizontally defined surface parcels, is the key concept pushing property rights from a $2 \mathrm{D}$ to a $3 \mathrm{D}$ framework. Ownership, as the most important right to property, can be documented not only in text and in parcelbased 2D maps but also registered in terms of spatial extent, because it is determined and identified in the physical world. Spatial modeling of ownership can succeed in representing the spatial extent that is defined by the property's physical space.

For land management, a polyhedral container can be used for clarifying spatial rights to the use of land space. A PLC-based compatible 3D data model is an effective means to represent both $2 \mathrm{D}$ and 3D property, which is especially useful in the ongoing development of 3D cadastral systems, since 2D cadastres are the prevailing paradigm for the management of property. For housing property, the ownership may have a complex structure, so an individual polyhedral container may fail to capture the spatial extent of the ownership because of the heterogeneous rights to parts of property caused by sharing space. Therefore, explicitly demarcating the spatial extent of each part, clarifying the structure of ownership, and linking them with the legal spatial extent are the critical tasks for the precise management of properties.

It should be also noted that spatial modeling of property depends largely on its legal and institutional system. Here, cases in China are taken as an example, and the above-presented modeling details and data model are specific to the Chinese context. Nevertheless, it provides an available exemplar for applications in other legal systems, and its modeling paradigm may be very helpful for developing property management systems for various kinds of 3D property.

Acknowledgements This study is funded by the National Natural Science Foundation of China (No. 41871298)

\section{References}

Aien A, Kalantari M, Rajabifard A, Williamson I, Wallace J (2013) Towards integration of 3D legal and physical objects in cadastral data models. Land Use Policy 35:140-154

Amirebrahimi S (2012) BIM for facilitation of land administration systems in Australia. In: Rajabifard A, Williamson I, Kalantari M (eds) A national infrastructure for managing land information. Center for Spatial Data Infrastructures and Land Information, University of Melbourne, Melbourne, $\mathrm{p} 95$

Arens C, Stoter J, van Oosterom P (2005) Modelling 3D spatial objects in a geo-DBMS using a 3D primitive. Comput Geosci 31(2):165-177

Çağdaş V (2013) An application domain extension to CityGML for immovable property taxation: a Turkish case study. Int J Appl Earth Obs Geoinf 21:545-555

Carlson E (1987) Three-dimensional conceptual modeling of subsurface structures. In: Proceedings of Auto-Carto 8. ACSM/ASPRS, Falls Church, Virginia, pp 336-345

Cohen-Steiner D, De Verdiere C, Yvinec M (2004) Conforming Delaunay triangulations in 3D. Comput Geom 28(2-3):217-233 
El-Mekawy M, Paasch J, Paulsson J (2014) Integration of 3D cadastre, 3D property formation and BIM in Sweden. In: 4th international workshop on 3D Cadastres, Dubai, 9-11 Nov. International Federation of Surveyors (FIG)

Foley JA, DeFries R, Asner GP, Barford C, Bonan G, Carpenter SR (2005) Global consequences of land use. Science 309(5734):570-574

Góźdź K, Pachelski W, Van Oosterom P, Coors V (2014) The possibilities of using CityGML for $3 \mathrm{D}$ representation of buildings in the cadastre. In: Proceedings 4th international workshop on 3D cadastres, Dubai, 9-11 Nov 2014. International Federation of Surveyors (FIG)

Guo R, Ying S (2010) 3D cadastre analysis and data delivery. J China Land Sci 24(12):45-51 (in Chinese)

Guo R, Li L, Ying S, Luo P, He B, Jiang R (2013) Developing a 3D cadastre for the administration of urban land use: A case study of Shenzhen, China. Comput Environ Urban Syst 40:46-55

Jazayeri I, Rajabifard A, Kalantari M (2014) A geometric and semantic evaluation of 3D data sourcing methods for land and property information. Land Use Policy 36:219-230

Kalantari M, Rajabifard A, Wallace J, Williamson I (2008) Spatially referenced legal property objects. Land Use Policy 25(2):173-181

Karabin M (2014) A concept of a model approach to the 3D cadastre in Poland: technical and legal aspects. In: Proceedings 4th international workshop on 3D Cadastres, Dubai, 9-11 Nov 2014. International Federa-tion of Surveyors (FIG)

Li L, Wu J, Zhu H, Duan X, Luo F (2016) 3D modeling of the ownership structure of condominium units. Comput Environ Urban Syst 59:50-63

Li L, Lei Y, Tang L, Yan F, Luo F, Zhu H (2019) A 3D spatial data model of the solar rights associated with individual residential properties. Comput Environ Urban Syst 74:88-99

Miller GL, Talmor D, Teng SH, Walkington N, Wang H (1996) Control volume meshes using sphere packing: generation, refinement and coarsening. In: Proceedings of 5th international meshing roundtable, Pittsburgh, PA, pp 47-61

Molenaar M (1990) A formal data structure for 3D vector maps. In: Proceedings of EGIS'90, Amsterdam, pp 770-781

Open Geospatial Consortium (2012) Geography markup language (CityGML) encoding standard. OGC

Paulsson J, Paasch JM (2011) 3D property research—a survey of the occurrence of legal topics in publications. In: The 2nd international workshop on 3D Cadastres, Delft

Penninga F, Oosterom P, Kazar BM (2006) A tetrahedronized irregular network based DBMS approach for 3D topographic data modeling. In: Reidl A, Kainz W, Elmes GA (eds) Progress in spatial data handling. Springer, New York, pp 581-598

People's Republic of China (2000) Specifications for estate surveying. GB/17986-2000. TMOCATSBOSA Mapping

People's Republic of China (2007) The Real Right Law of People's Republic of China

Pouliot J, Vasseur M, Boubehrezh A (2011) Spatial representation of condomini-um/co-ownership: comparison of Quebec and French cadastral system based on LADM specifications. In: Proceedings of the 2nd international workshop on 3D ca-dasters, organized by FIGURE EuroSDR and TU Delft, Delft: The Netherlands

Pouliot J, Vasseur M, Boubehrezh A (2013) How the ISO 19152 land administration domain model performs in the comparison of cadastral systems: a case study of condominium/co-ownership in Quebec (Canada) and Alsace Moselle (France). Comput Environ Urban Syst 40:68-78

Rajabifard A, Williamson I, Marwick B, Kalantari M, Ho S, Shojaei D (2013) 3D-Cadastre, a multifaceted challenge. In: Proceedings of the XXV FIG International Congress 2014, Kuala Lumpur. International Federation of Surveyors (FIG)

Si H, Gartner K (2005) Meshing piecewise linear complexes by constrained Delaunay tetrahedralizations. In: Proceedings of the 14th international meshing roundtable. Springer, New York, pp $147-163$

Sorensen EM (2011) 3 Dimensional property rights in Denmark, 3D property design is workingvisualization not. In: 2nd international workshop on 3D Cadastres, Delft, pp 521-530 
Stoter JE (2004) 3D cadastre. Ph.D. thesis, Delft University of Technology

Stoter JE, Ploeger H, van Oosterom P (2013) 3D cadastre in the Netherlands: developments and international applicability. Comput Environ Urban Syst 40:56-67

Stubkjær E (2004) Cadastral modeling: grasping the objectives. In: Proceedings of Joint FIG Commission 7 and COST Action G9 Workshop on Standardization in the Cadastral Domain, Bamberg, Germany

Thompson RJ (2007) Towards a rigorous logic for spatial data representation. Ph.D.'s Thesis, Delft University of Technology, The Netherlands

Turner BL, Lambin EF, Reenberg A (2007) The emergence of land change science for global environmental change and sustainability. Proc Natl Acad Sci 104(52):20666-20671

van der Molen P (2003) Institutional aspects of 3D cadastres. Comput Environ Urban Syst 27(4):383-394

Wenninger MJ (1974) Polyhedron models. Cambridge University Press, Cambridge

Ying S, Guo R, Li L, Van Oosterom P, Stoter J (2014) Construction of 3D volumetric objects for a 3D cadastral system. Trans GIS 19(5):758-779

Zlatanova S (2000) 3D GIS for urban development. Ph.D. thesis, Graz University of Technology

Zulkifli NA, Rahman AA, Van Oosterom P (2015). An overview of 3D topology for LADM-based objects. In: ISPRS Joint International Geoinformation Conference, Kuala Lumpur, Malaysia
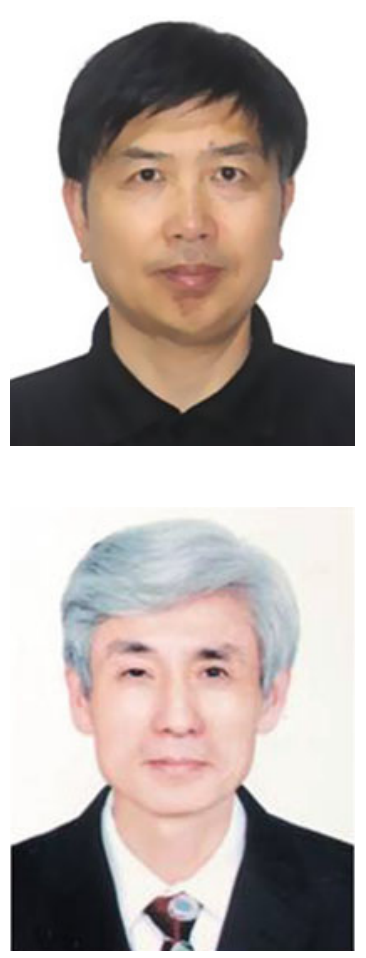

Lin Li is a Professor and Luojia Outstanding scholar of Wuhan University, with a Ph.D. degree in Photogrammetry and Remote Sensing. He has been working at the School of Resource and Environmental Sciences, Wuhan University, and is currently interested in spatial modeling for 3D cadastre, indoor modeling from point cloud data, and the integration of semantic location.

Renzhong Guo is a Professor and Director of the Institute for Smart Cities at Shenzhen University. He is a member of the Chinese Academy of Engineering, and vice president of both the Chinese Society of Urban Studies and the China Land Science Society, and currently interested in the smart city. 

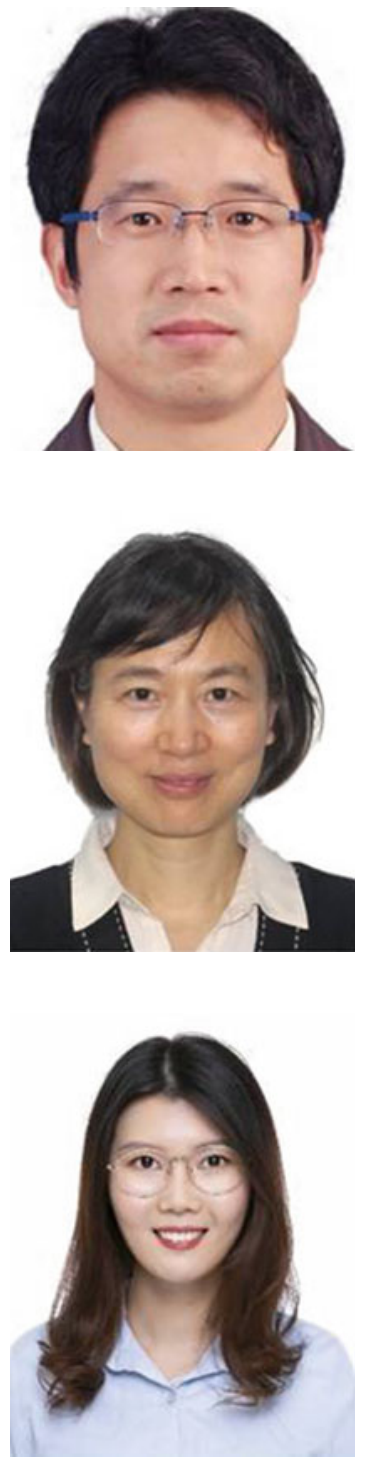

Dr. Shen Ying is a Professor at the School of Resource and Environmental Sciences, Wuhan University, and a member of the "China National Special Support Program for High-Level Personnel." His interests include 3DGIS, cartography, and spatial analysis.

Haihong Zhu is a Professor in the School of Resource and Environmental Science, Wuhan University. She received her Ph.D. degree from Wuhan University. Her current research interests focus on 3D modeling and visualization, geographical ontology, map design, and navigation digital mapping.

Jindi Wu received a master's degree in Cartography and Geographical Information Systems from Wuhan University in 2016, focusing on 3D modeling of the ownership structure of condominium units, and is currently working at Tencent Tongtu Data Technology Company Limited, engaged in digital map production management. 


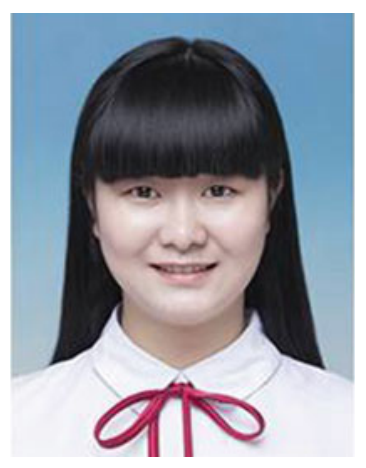

Chengcheng Liu is a Ph.D. candidate in the School of Resource and Environmental Sciences, Wuhan University, majoring in Cartography and Geographic Information Engineering, and is currently interested in spatial modeling for 3D cadastre and Cartography.

Open Access This chapter is licensed under the terms of the Creative Commons Attribution 4.0 International License (http://creativecommons.org/licenses/by/4.0/), which permits use, sharing, adaptation, distribution and reproduction in any medium or format, as long as you give appropriate credit to the original author(s) and the source, provide a link to the Creative Commons license and indicate if changes were made.

The images or other third party material in this chapter are included in the chapter's Creative Commons license, unless indicated otherwise in a credit line to the material. If material is not included in the chapter's Creative Commons license and your intended use is not permitted by statutory regulation or exceeds the permitted use, you will need to obtain permission directly from the copyright holder.

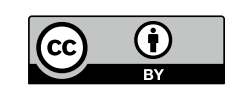

